\section{Pharmacies receiving}

\section{massive rebates from}

\section{generic drug-makers}

$\mathrm{R}$

evelations about massive rebates to pharmacies from generic drug manufacturers rocked committee hearings on the Ontario government's controversial Transparent Drug System for Patients Act 2006.

The legislation, passed in late June, aims to achieve savings in the Ontario Drug Benefit (ODB) program, which costs $\$ 3.4$ billion a year, by allowing more interchangeability of generic drugs for brand-name drugs. It will make the system "more efficient, more transparent, more accountable, more understandable," MPP Tim Peterson told the legislature. (The ODB program provides drugs at no direct cost, except for a small co-payment, to senior citizens and social assistance recipients.)

Much to the public's surprise, however, it was revealed during committee hearings on Bill I02 that pharmacies were receiving "rebates" from generic drug manufacturers of up to $60 \%$ of the dollar value of drugs that they sold. That number was higher even than the ministry's estimate of $40 \%$, said Helen Stevenson, special consultant to the Ministry of Health.

Marc Kealey, chief executive officer of the Ontario Pharmacists' Association (OPA), likened the rebates to volume discounts in a competitive market. There are multiple, generic versions of some common drugs and manufacturers compete, based on the size of the rebate, to have pharmacies stock their drugs, he explained.

Kealey took exception to suggestions that such rebates were unethical. Money from rebates has been used to educate pharmacists and patients, and invest in infrastructure upgrades such as information technologies, not to line their pockets, he said.

The totals are hefty. By the OPA's own calculations, $40 \%$ of the ODB program's share of spending on generic drugs in 2005 amounted to $\$ 228$ million. (A total of \$1.6 billion was spent on generics in Ontario's public and private markets that year.)

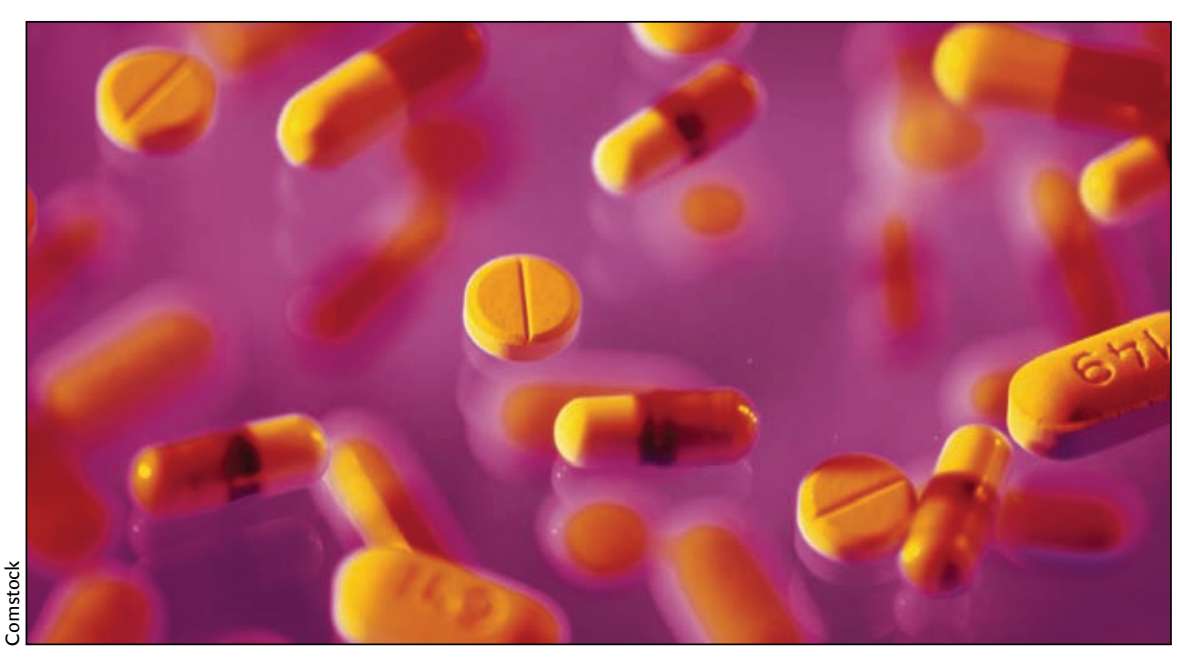

It was revealed during committee hearings on Bill 102 that pharmacies were receiving "rebates" from generic drug manufacturers of up to $60 \%$ of the dollar value of drugs that they sold.

Stevenson speculated that the size of rebates, which are banned in the US, goes a long way toward explaining the fact that Canada has, according to the Patented Medicines Prices Review Board, the most expensive generic drugs in the developed world.

The Ontario Medical Association (OMA) and the OPA spoke in favour of Bill I02, which amends the Ontario Drug Benefit Act and the Drug Interchangeability and Dispensing Fee Act. Its features include:

- A new executive officer position empowered to list new drugs on the formulary. The current system requires new listings to be approved by an Order in Council - a timeconsuming and cumbersome procedure. The officer would act on recommendations from a Committee to Evaluate Drugs, essentially a renamed Drug Quality and Therapeutics Committee with new consumer/public representation.

- A mechanism to replace Section 8, under which Ontario doctors filled out 143370 special application forms in 2004 to obtain prescription drugs not listed on the provincial formulary. The Act calls for a new mechanism that allows conditional listing of drugs and some exceptional access. As well, the executive officer may authorize retroactive access and coverage.

- Elimination of the $\$ 25$ cap placed on the $8 \%$ mark-up on drugs; an increase in the dispensing fee to $\$ 7$ from $\$ 6.54$; and the introduction of a "cognitive service fee" to compensate pharmacists for professional work, such as counselling patients.

The province says it will save money by putting pressure on the price of generics. The government will negotiate agreements to pay generics $50 \%$ of the price of the off-patent brand-name product that was copied, although the price to be listed in the provincial formulary will likely be on the order of $70 \%$ or $63 \%$ of the brand-name cost.

The province also says it will ban "rebates" but allow pharmacies to receive, from generic manufacturers, $20 \%$ of the listed drug cost as a "professional allowance." (A code of conduct is being drawn up, with OPA involvement, to spell out how that $20 \%$ could be spent.) The latter prohibition, however, won't apply to drugs purchased under employer-sponsored health plans or by individuals who pay out-of-pocket for their therapies. In the case of corporate plans, the prices listed in the formulary are often used as the benchmark price.

Even those who applaud many of the proposed changes note there are many unresolved issues that won't be clarified until the regulations are published, by October.

Once supportive of the legislation, the Canadian Generic Pharmaceutical Association is now taking a more cau- 
tious view. "We're quite concerned," said President Jim Keon. "We won't give our support until we see and understand how the regulations will work."

The brand-name industry is taking a similar stance, said Rx\&D spokesperson Jacques Lefebvre. - Ann Silversides, Toronto

DOI:I0.1503/cmaj.o6ogo4

\section{Systemic changes needed}

\section{to resolve queues}

S ystemic changes to the health care system are the only longterm means of ensuring that Canadians aren't forever queuing up for medical procedures once the current $\$ 5.5$-billion fund to fix wait-time problems runs dry, Federal Advisor on Wait Times Dr. Brian Postl says.

One-time money spent ramping up volumes to resolve wait lists for select procedures is but a short-term solution to the problem of queues, the chief executive officer of the Winnipeg Regional Health Authority said in an interview. "Eventually, the money runs out and you haven't bought change."

In his final report to the government, released June 30, Postl argues "a transformation that puts patients at the centre of the system" is in order if wait times are to be ultimately reduced.

Among requisite elements of the recommended transformation:

- more use of common, regional wait lists, rather than lists kept by individual doctors;

- prioritization of patients by acuity and concomitant slotting into first available slots of intervention;

- a \$2.4-billion/5-year outlay for healthrelated information technologies;

- system-wide electronic health records to give health professionals "current and accurate information on which to base a diagnosis or treatment decision";

- digitalization of diagnostic images;

- electronic patient registries;

- provincial Colleges of Physicians and Surgeons monitoring of "professional practice with respect to physi- cian management of wait times";

- appointment of a provincial wait time "champion" to coordinate the response of regional health authorities and institutions, as well as develop and disseminate best practices within a national network;

- identification of additional priority areas in which benchmarking is necessary.

The latter recommendation stems from concerns that so-called "Cinderella diseases" that weren't targeted by the nation's health ministers in the 2004 First Ministers' Io-Year Action Plan to Strengthen Health Care to reduce wait times in 5 priority areas (cancer, cardiac, diagnostic imaging, joint replacement and sight restoration) are now being starved out by the focus on those conditions.

There's "anecdotal evidence" that wait lists are now longer for some procedures than they once were because of the focus on the 5 , as human resources are poured into those conditions, Postl says. "So if you're in a region or province that may have a shortage of anethesia, for example, and you're cranking up your cardiac and hips and knees, do you divert your anesthesia resource into those areas and does that mean it comes from some other area, which creates a longer waiting list? It's something we have to keep tabs on, because I'm not sure the Canadian public sees the exchange of waiting lists as a positive thing." - Wayne Kondro, CMAJ

DOI:Io.I503/cmaj.06089o

\section{News@a glance}

CMA presidency challenge: Delegates to this month's annual general meeting of the CMA face an unexpected choice as Vancouver family physician Dr. Jack Burak will now challenge British Columbia Medical Association nominee Dr. Brian Day for the CMA's top job in 2007-08. Burak, a former BCMA president and staunch advocate of Canada's publicly funded medicare system, contended Day's avowed support for private funding and the private delivery of health care are anathema to the majority of Canadian physicians. Day, who runs the controversial Cambie Surgery Centre, narrowly edged Burak in the BCMA election for the CMA nomination.

NPs by the number: The number of nurse practitioners increased $17 \%$ between 2004 and 2005, states a new report from the Canadian Institute for Health Information. There were 1026 NPs in 2005, up from 878 the year before.

Cost of waiting: Excessive waits for treatment constitute an enormous drain on the economy, concludes a study by the Centre for Spatial Economics for the Canadian Medical Association and British Columbia Medical Association. The study projects that some $\$ \mathrm{I} .8$ billion in economic production, along with $\$ 500$ million in tax revenues will be lost in 2006 as a result of waits over and above recommended benchmark times for 4 procedures (total joint replacement, MRI scans, cataract and coronary artery bypass graft surgery) in BC, Alberta, Saskatchewan and Ontario. These esti-

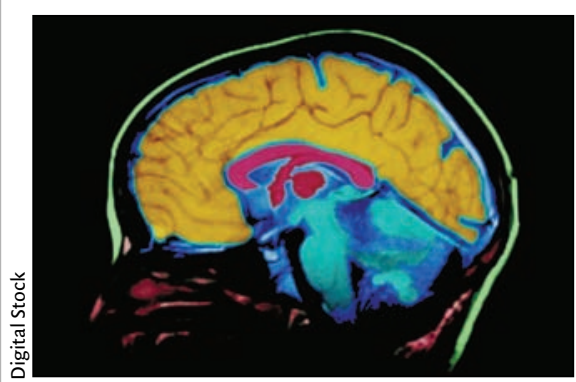

mates are based on the projected loss of productivity by patients and their caregivers, and the additional cost to the health care system that accrues from patients having to "attend medical appointments, submit to tests and procedures, and take medications that would not have been required had their wait times not exceeded the maximum recommended."

Webaholics: People with Internet addiction disorder (IAD) will likely start flooding physicians and psychotherapists offices in coming years, predicts a nursing professor at LaSalle University in Philadelphia. Dr. Diane Wieland states that IAD will strike as many as $10 \%$ of all World Wide Web users (Perspectives in Psychiatric Care 2005;4I[4]:153-6I). Possible symptoms include cyber shakes (psychomotor agitation and typing 